\title{
Dampak Dwelling Time Terhadap Layanan Ekspor Impor di Pelabuhan Tanjung Emas Semarang
}

\author{
Ario Hendartono ${ }^{1)}$, Christine Widilestari ${ }^{2)}$ \\ ${ }^{1)}$ Politeknik Maritim Negeri Indonesia, \\ Jalan Pawiyatan Luhur I/1, Bendan Duwur Semarang, Jawa Tengah, Indonesia 50233 \\ Email: ariohend@polimarin.ac.id ${ }^{1)}$, christinewidi@polimarin.ac.id ${ }^{2)}$
}

\begin{abstract}
Abstrak
Dwelling time ideal harus sesuai target keuntungan pasar. World Bank (2011), pengertian dwelling time adalah waktu yang dihitung mulai petikemas dibongkar dan diangkat dari kapal sampai petikemas tersebut meninggalkan terminal petikemas pelabuhan melalui pintu utama. Proses dwelling time di pelabuhan yaitu pre-clearance, customs clearance, dan post- clearance. Tujuan penelitian ini di Pelabuhan Tanjung Emas (1) Mengetahui faktor-faktor penyebab lamanya dwelling time (2) Mengetahui dampak dwelling time pada ekspor, impor (3) Mengetahui tindakan mitigasi. Jenis penelitian adalah penelitian kualitatif, data yang dibutuhkan diharapkan dapat diperoleh dari observasi, wawancara terkait kebijakan, strategi dan kenyataan di lapangan. Data yang diperoleh sebagai berikut : (1) Faktor-faktor dwelling time antara lain: proses pemeriksaan dokumen, fisik barang atas klasifikasi Kepabeanan; data tanggal PIB dan SPPB seringkali tidak detail, lama pemrosesan peti kemas di TPKS seringkali tidak diketahui; pengguna jasa tidak melengkapi dokumen secara jelas. (2) Dampak lamanya proses $d$ welling time pada layanan ekspor dan impor antara lain: proses ekspor tidak terlalu berpengaruh; dwelling time proses impor lebih lama daripada ekspor peti kemas yang masuk TPKS dokumennya masih harus diperiksa karantina dan Bea Cukai. (3) Tindakan mitigasi, kebijakan mengatur pengeluaran kontainer baik isi maupun kosong ke PLP setelah 5 hari dan setelah 10 hari harus dipindahkan ke depo swasta.
\end{abstract}

Kata Kunci : customs clearance, dwelling time, pre-clearance, post-clearance

\begin{abstract}
The ideal dwelling time has to match the target market profit. World Bank (2011), the definition of dwelling time is the time calculated from the time the containers are unloaded and lifted from the ship until the containers leave the port container terminal through the main gate. The process of dwelling time at the port is pre-clearance, customs clearance and post-clearance. The purpose of this research at the Port of Tanjung Emas (1) Knowing the factors that cause the long dwelling time (2) Knowing the impact of the dwelling time on exports, imports (3) Knowing the mitigation measures. This type of research is qualitative research, the data required is expected to be obtained from observations, interviews related to policies, strategies and realities in the field. The data obtained are as follows: (1) Dwelling time factors, among others: document inspection process, physical goods based on Customs classification; data on PIB and SPPB dates are often not detailed, the length of time for container processing at TPKS is often unknown; service users do not clearly complete the document. (2) The impact of the dwelling time process on export and import services, among others: the export process does not really have an effect; The import process dwelling time is longer than the export of containers that enter TPKS, the documents still have to be inspected by quarantine and Customs. (3) Mitigation measures, the policy regulates the release of both filled and empty containers to the PLP after 5 days and after 10 days they must be moved to a private depot.
\end{abstract}

Key words: dwelling time, pre-clearance, customs clearance, post-clearance. 


\section{PENDAHULUAN}

Indonesia terdiri dari ribuan pulau dengan jumlah lebih dari 17.000 pulau yang tiga perempat bagian wilayah Indonesia merupakan perairan, dan berada di antara dua benua dan dua samudera yaitu benua Asia dan benua Australia serta samudra Hindia dan samudera Pasifik. Salah satu moda transportasi yang sesuai untuk menghubungkan pulaupulau tersebut adalah kapal laut.

Salah satu pelayanan yang berpengaruh pada supply chain atau rantai pasok adalah dwelling time. Dwelling time sendiri menurut World Bank (2011) "defined port dwell time as the time that counted start from when cargo (containers) is being unloaded from the ship until the container itself is leaving the terminal through the main door, yang artinya waktu yang dihitung mulai saat muatan atau kargo diturunkan dari kapal sampai petikemas (kontainer) tersebut sendiri keluar terminal melalui pintu utama. Down dan Leschine (1990); Doerr dan Sanchez (2006); Chung (1993) menyampaikan "the productivity of a container terminal is related to an efficient use of labour, equipment and land, and is commonly measured as a function of the ship turnaround time, the transfer rate of containers and the dwell times of the cargo at the port, yang artinya produktifitas terminal petikemas terkait dengan penggunaan tenaga kerja, peralatan, dan tanah yang efisien, dan diukur dengan tepat sebagai fungsi dari waktu penyelesaian kapal, laju pengiriman peti kemas dan waktu lamanya muatan di pelabuhan. Dengan demikian untuk menghasilkan dwelling time yang ideal dan sesuai dengan target keuntungan pasar harus dilihat sebagai sesuatu sistem yang saling terkait baik penggunaan sumber daya manusianya yang tentunya sumber daya manusia yang profesional, kesiapan peralatan baik waktu mempersiapkannya, kecepatannya, perawatannya. Selain itu jenis serta tipenya, serta lahan baik luasnya yang berpengaruh pada penumpukan kontainer atau petikemas, jaraknya serta infrastrukturnya yang dapat menopang percepatan akses yang diperlukan agar tercapai kecepatan serta tingkat efisiensi yang tinggi.

Pada penelitian dilakukan telaah atas penelitian sebelumnya, dimana menurut Ricardianto, Suhalis, dan Sirait (2019) beberapa penyebab terjadi tingginya dwelling time di Pelabuhan Tanjungpriok antara lain : (1) Pertumbuhan kegiatan yang cukup tinggi pada ocean going (21\%/tahun), domistik (23\%/tahun); (2) Belum siapnya infrastruktur dan suprastruktur; (3) Kualitas SDM kurang; (4) Risk Management System dan metode pemeriksaan barang yang belum optimal; (5) Tempat pemeriksaan Fisik Terpadu (TPFT) belum berjalan baik; (6) Sikap para pemilik barang/importir terkesan menjadikan pelabuhan sebagai tempat penimbunan barang. Di penelitian lain, Anita dan Asmadewa (2017) menyampaikan beberapa pengguna jasa memiliki titik mulai yang berbeda pada alur impor yang dilaksanakan. Prathama, Suwandi, dan Soeboer (2017) di penelitian lain menyampaikan TPK Koja masih sangat beresiko terhadap kemungkinan terjadinya kepadatan arus petik emas di masa mendatang karena belum mencapai standar regulasi pemerintah. Menurut Narindra, Musadieq, dan Supriono (2016), terdapat pengaruh positif yang signifikan dari Dweeling Time $(\mathrm{X})$ terhadap pendapatan pelabuhan (Y). Adanya pengaruh positif tersebut dapat dikatakana bahwa apabila semakin lama dweeling time maka pendapatan pelabuhan semakin meningkat khususnya pada sisi biaya penumpukan. Pada hasil penelitian Sarjiyanto dan Muslimin (2017) disampaikan bahwa dwelling time di TPKS mencapai 5,6 hari dan cenderung menurun dari periode Januari 2014 sampai Maret 2015.

Menurut Artakusuma (2012) dalam Narindra dkk. (2016, hal. 52) saat ini tingkat $d$ welling time yang dihadapi oleh beberapa pelabuhan di Indonesia cukup tinggi. Rata-rata dwelling time di Indonesia adalah kisaran 5 hingga 7 hari. Hal ini sangat lama dibandingkan dengan dwelling time di beberapa negara seperti Chabang di Thailand 5 hari. Hal tersebut juga diperkuat dengan hasil wawancara pada pengguna layanan di Pelabuhan Tanjung Emas, meskipun berdasarkan pengakuan yang bersangkutan waktu dwelling time di Pelabuhan Tanjung Emas tidak terlalu berdampak secara signifikan terhadap bisnisnya. Dalam hal ini terdapat fenomeno yag menarik di satu sisi pemerintah menekan manajemen pelabuhan untuk mengurangi dwelling time, tetapi di sisi lain terjadinya $d w e l l i n g$ time juga dapat membawa keuntungan beberapa pihak. Melihat data tersebut di atas, maka ada ketertarikan untuk meneliti dwelling time di pelabuhan Tanjung Emas dalam layanan Eksport Import petikemas.

Tujuan yang ingin diperoleh dari penelitian ini antara lain (1) Mengetahui faktor-faktor apa sajakah yang menjadi penyebab lamanya dwelling time di Pelabuhan Tanjung Emas; (2) Mengetahui dampak lamanya proses $d w e l l i n g$ time pada layanan ekspor dan impor di Pelabuhan Tanjung Emas; (3) Mengetahui tindakan mitigasi yang diambil Pelabuhan Tanjung Emas Semarang untuk mengurangi dwelling time. Adapun manfaat dari penelitian adalah (1) Hasil penelitian ini dapat digunakan sebagai acuan dalam menganalisa lamanya dwelling time pada suatu pelabuhan serta analisa dampaknya terhadap layanan ekspor impor; (2) Hasil penelitian ini dapat digunakan sebagai pertimbangan langkahlangkah yang dapat dilakukan dalam mengurangi dwelling time pada suatu pelabuhan.

\section{METODE PENELITIAN}

Grand theory pada penelitian ini adalah Teori Kendala/Theory of Constraint. Teori Kendala atau yang dikenal Theory of Constraint (TOC) adalah pengembangan filosofi manjemen sistem yang pertama kalinya dikembangkan Godratt dan Fox dalam Gusnardi (2010: hal. 337). Dalam TOC hal yang mendasar adalah keterbatasan yang dapat menentukan kinerja dari suatu sistem. Susty A (1999) : "The theory of constrain (TOC) / teori kendala merupakan 
teknik strategik untuk membantu perusahaan secara efektif meningkatkan faktor keberhasilan kritis yang sangat penting waktu siklus, yaitu lamanya bahan diubah menjadi produk selesai/produk jadi” (Gusnardi, 2010 : hal 337 ). Dalam penelitian ini TOC digunakan untuk menganalisa kondisi yang terjadi dan kebijakan yang diambil dalam kaitannya dengan dwelling time.

Tipe penelitian yang digunakan pada penelitian ini adalah tipe deskriptif kualitatif, dengan tujuan memperoleh gambaran kondisi yang terjadi melalui fakta-fakta atau gejala yang nampak pada proses Dwelling Time. Metode deskriptif bertujuan untuk memecahkan masalah yang ada pada saat ini. Metode ini menjelaskan, menganalisa dan mengklasifikasi melalui survei, wawancara, daftar pertanyaan, observasi (Nawawi dan Martini, 1996: 73).

Penelitian ini merupakan penelitian kualitatif yang menggunakan informan sebagai salah satu sumber data terbesar, sehingga tidak menggunakan istilah populasi dan sampel. Teknik pemilihan informan menggunakan teknik Purposive Sampling yaitu penentuan yang tidak mempertimbangkan strata, kedudukan, pedoman atau wilayah tertentu, tetapi berdasarkan atas tujuan dan pertimbangan yang terkait dengan permasalahan penelitian (Sugiyono, 2011: hal. 85). Dalam penelitian ini yang menjadi informan adalah para pemangku kebijakan dan pelaksana lapangan di lingkungan TPKS, mantan pejabat TPKS di lingkungan pelabuhan Tanjung Emas Semarang dan pengusaha ekspor impor.

Data yang diperoleh pada penelitian ini berupa data deskriptif yang berasal dari hasil observasi dan wawancara yang dilakukan terkait dengan hal-hal yang bersifat kebijakan, strategi dan kenyataan di lapangan. Selain itu diperoleh data-data lain berupa dokumen, dan catatan lapangan yang terkait dengan data penelitian. Sumber data dari penelitian ini diperoleh dari dua sumber yaitu sumber data primer adalah responden atau orang-orang yang terlibat langsung dengan obyek penelitian ini. Sedangkan sumber data sekunder adalah laporan-laporan, dokumen-dokumen, brosurbrosur, buku-buku pustaka yang memuat bahasan tentang obyek penelitian, artinya penulis memperoleh informasi secara tidak langsung (Sugiyono, 2011: hal. 308).

Ghony dan Almanshur (2013: hal.163) mengatakan bahwa dalam penelitian kualitatif instrumen utama adalah peneliti sendiri, untuk mencari data dengan berinteraksi secara simbolik dengan informan. Oleh karena itu dalam upaya memperoleh data penelitian digunakan beberapa prosedur pengumpulan data yang satu dengan lainnya saling melengkapi sehingga diperoleh data yang dibutuhkan. Ada tiga prosedur pengumpulan data yang digunakan yaitu observasi partisipatif, wawancara mendalam (depth interview), dan studi kepustakaan.

\section{HASIL DAN PEMBAHASAN}

Setelah ijin didapat dari manajemen Terminal Peti Kemas Semarang untuk mendapatkan data tentang dampak dwelling time terhadap layanan ekspor impor di pelabuhan Tanjung Emas Semarang, maka proses pengambilan data dilakukan. Dari hasil observasi langsung di lapangan yang dipandu oleh mantan pejabat TPKS di lingkungan pelabuhan Tanjung Emas Semarang dan masih diberi kepercayaan sebagai narasumber, serta wawancara secara langsung ataupun dalam bentuk daftar pertanyaan tertulis oleh pejabat yang berwenang di lingkungan TPKS maka diperoleh hasil penelitian dalam bentuk data primer dan sekunder. Data primer didapat dari observasi langsung kegiatan di lapangan, di ruang monitoring serta wawancara dan data sekunder merupakan kajian dari berbagai pihak yang terkait pada kegiatan dwelling time.

\subsection{Hasil}

Berdasarkan uraian diatas, berikut ini akan disampaikan hasil penelitian yang diperoleh sebagai berikut:

\subsubsection{Kondisi Dwelling Time di Terminal Peti Kemas Semarang}

Dwelling time di Terminal Peti Kemas Semarang saat ini berkisar 4 hari, termasuk didalamnya petikemas Full atau Empty (berdasar data yang dikirim ke Indonesia National Single Window (INSW)). Dengan angka tersebut, masih dalam kewajaran dan dapat diterima. Berdasarkan data TPKS batas tertinggi yang berpengaruh ke biaya dwelling time di TPKS adalah 5 hari, selebihnya harus segera dikeluarkan atau dipindahkan ke Pindah Lokasi Penumpukan (PLP).

Dwelling time di TPKS Pelabuhan Tanjung Emas sudah dapat ditekan dengan alat yang moderen yaitu ARTG (Automated Rubber Tyred Gantry) sehingga mempercepat proses bongkar muat container. Hal tersebut telah menunjukkan peningkatan dibandingkan hasil penelitian Sarjiyanto dan Muslimin (2017) yang menyatakan bahwa dwelling time di TPKS pelabuhan Tanjung Emas Semarang dari Januari 2014 hingga Maret 2015 sekitar 5,6 hari. Pada gambar 1. Menunjukkan perbandingan biaya logistik terhadap dwelling time, sedangkan pada gambar 2 menunjukkan grafik dwelling time TPKS tahun 2019.

\subsubsection{Kondisi Tahapan-Tahapan Dweeling Time di TPKS}

Terdapat perbedaan terhadap pengertian mengenai pre clearance, custom clearance dan post clearance karena ketersediaan data antara TPKS dan Bea Cukai dan masing-masing pihak sudah mengetahui hal tersebut. Perbedaan pengertian PreClearance, Custom Clearance dan Post Clearance dijelaskan seperti pada gambar 3. 


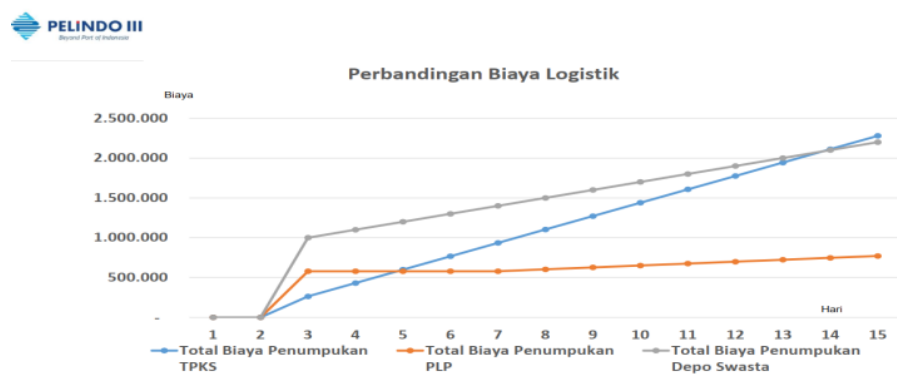

Gambar 1. Perbandingan Biaya Logistik atas Dwelling Time Sumber: Data Primer (TKPS, 2019)

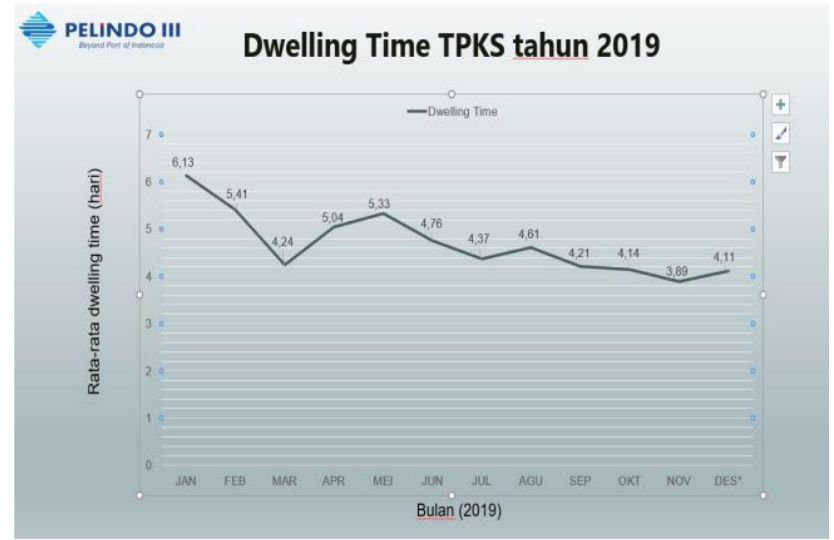

Gambar 2. Dwelling Time 2019 TPKS (INSW)

Sumber: Data Sekunder (TPKS, 2019)

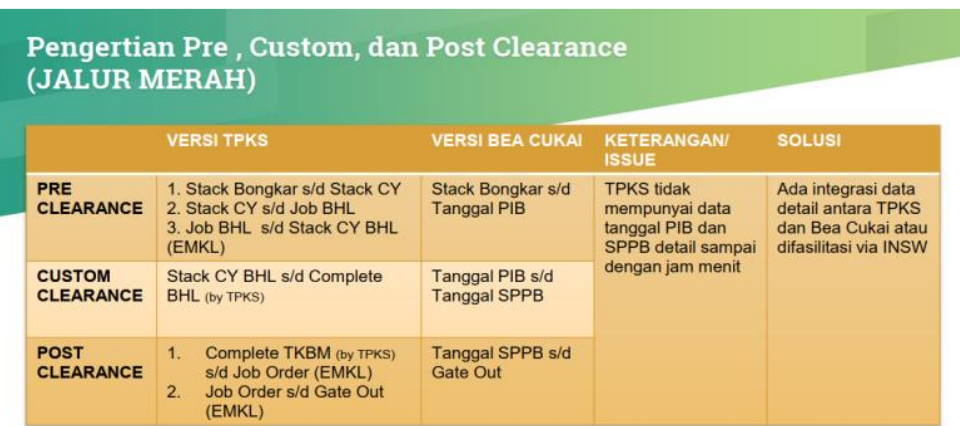

Gambar 3. Pengertian Pre Clearance, Custom Clearance dan Post Clearance Sumber: Data Sekunder (TPKS, 2019)

\subsubsection{Faktor-Faktor Penyebab Dwelling Time}

Pada intinya terdapat dua jalur utama Bea Cukai yakni jalur merah atau jalur hijau. Tanggung jawab TPKS terhadap penyebab dwelling time sangat kecil, dan pengguna jasa sendiri adalah penyumbang faktor dwelling time tertinggi baik jalur merah ataupun jalur hijau.

\subsubsection{Kendala Paling Signifikan Dweeling Time di Terminal Tanjung Emas Semarang}

Sampai saat ini sebenarnya di TPKS tidak ditemukan kendala yang signifikan, hanya beberapa kendala minor seperti waktu pergerakan ke CY khusus pemeriksaan (untuk jalur merah) yang harus memperhitungkan kapasitas CY dan ketersediaan alat penunjang.

\subsubsection{Dampak Dwelling Time Terhadap Proses Ekspor Impor Customer}

Untuk ekspor selama ini tidak ada masalah, dwelling time masih berkisar 3 hari dan itu normal karena open stack kapal adalah 5 hari, akan tetapi untuk impor dampak langsungnya adalah kepada importir/pemilik barang. 


\subsubsection{Dwelling Time Ekspor vs Impor}

Untuk ekspor waktu dwelling time lebih pendek. Untuk proses impor, dokumen kepabeanan saat masuk ke TPKS masih ada beberapa dokumen yang belum clear, sehingga masih perlu pemeriksaan baik dari karantina ataupun dari bea cukai, belum lagi faktor ketersediaan gudang dari sisi importer, sehingga dwelling time impor pasti lebih tinggi dari ekspor.

\subsubsection{Jalur Hijau dan Jalur Merah Bukan Merupakan Suatu Kendala Signifikan di TPKS yang Akan Mempengaruhi Dweeling Time}

Dari sisi terminal tidak ada kendala terkait pengaruh penjaluran jalur hijau. Untuk jalur merah ada peran TPKS rata-rata 0.5 hari saja untuk proses relokasi ke CY Pemeriksaan .

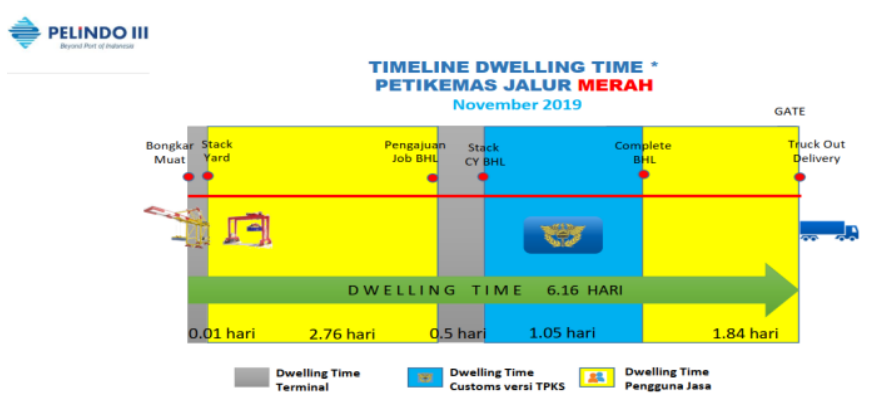

Gambar 4. Timeline Dwelling Time, Peran Masing-Masing Stakeholder (Versi TPKS) untuk Jalur Merah Sumber: Data Sekunder (TPKS, 2019)

PELINDO III

TIMELINE DWELLING TIME *

PETIKEMAS JALUR HIJAU/BC23/MTY

November 2019

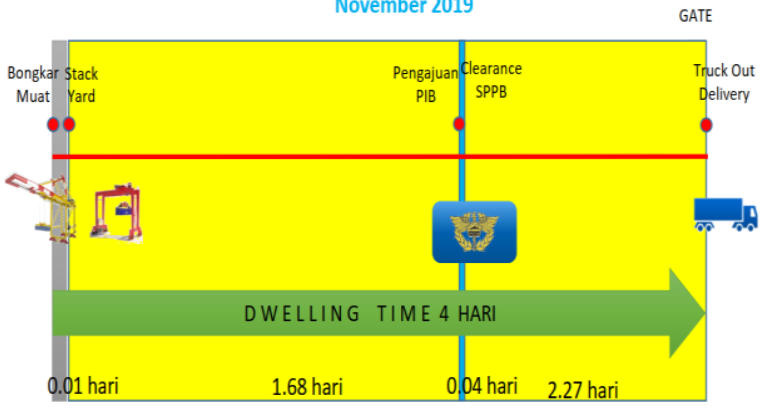

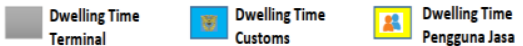

Gambar 5. Timeline Dwelling Time, Peran Masing Masing Stakeholder (Versi TPKS) untuk Jalur Hijau Sumber: Data Sekunder (TPKS, 2019)

\subsubsection{Strategi Untuk Memperkecil Dwelling Time di TPKS}

Strategi dalam upaya memperkecil dwelling time di TPKS adalah melakukan koordinasi dengan Bea Cukai untuk integrasi data-data yang diperlukan untuk mempercepat proses dokumen. Selain itu perlu menginfokan kepada pengguna jasa (agen pelayaran) setiap 2 minggu atas petikemas yang belum dilakukan pengeluaran lebih dari 10 hari dan melakukan kerjasama pengeluaran petikemas ke PLP dengan pihak di luar TPKS.

\subsubsection{Kondisi Dwelling Time di Singapura (2 Hari) Dibandingkan Dengan Pelabuhan Indonesia}

Di Singapura mayoritas petikemas merupakan transhipment (feeder vessel), sehingga yang masuk/keluar ke Singapura hanya sedikit jika dibanding yang ada di Indonesia. Di Pelabuhan Singapura juga merupakan kawasan free zone dimana dalam lingkungan terminal terdapat beberapa manufaktur/pengemasan sehingga petikemas tidak perlu keluar wilayah pelabuhan. Oleh sebab itu maka wajar bila di Singapura dwelling time hanya 2 hari. 


\subsubsection{Harapan Terhadap Pemerintah Kaitannya Dengan Dwelling Time}

Harapan dari TPKS adalah perlu dilakukan riset terhadap rantai cost logistics secara objektif dan menyeluruh, karena cost tidak hanya tergantung dari dwelling time, misal dari freight kapal, proses dokumen kepabeanan dan karantina, proses pengeluaran dari terminal, trucking, pergudangan/depo, demurage petikemas, sampai ke pabrik. Dengan adanya aturan $d$ welling time dari sisi customer/importir mungkin saja lebih banyak cost karena berlakunya tarif progresif, kemudian adanya pergerakan ke PLP dan lain-lain. Setelah diketahui cost logistic maka pemerintah dapat menerbitkan aturan yang dapat mengurangi cost tersebut.

\subsection{Pembahasan}

Hasil penelitian yang ditujukan menjawab pertanyaan penelitian sebagai berikut:

3.2.1. Faktor-faktor yang menjadi penyebab lamanya dwelling time di Pelabuhan Tanjung Emas.

Faktor- faktor penyebab dwelling time pada umumnya adalah adanya 2 jalur utama Bea Cukai dalam proses pengeluaran peti kemas impor yakni jalur merah dan jalur hijau. Menurut Asngadi (2017) menyatakan jalur merah adalah perlakuan pabean atas Pemberitahuan Impor Barang (PIB) karena memenuhi kriteria sebagai berikut : jenis barang yang tidak jelas serta tidak spesifik, tidak adanya nota intelijen, nilai pabean yang meragukan, reputasi importir yang jelek, tidak ada perintah pemeriksaan acak oleh computer.

Sedangkan jalur kuning yaitu pengeluaran barang atau kontainer impor dari kawasan pabean tanpa pemeriksaan fisik barang, tetapi tetap dilakukan penelitian dokumen sebelum penerbitan SPPB. Untuk jalur hijau adalah fasilitas yang diberikan importir, wajib membuat PIB dan dilakukan pemeriksaan dokumen PIB tanpa pemeriksaan fisik barang.

Dalam kaitan dengan jalur hijau dan jalur merah dari sisi TPKS tidak ada masalah pada dwelling time karena rata rata hanya 0,5 hari saja untuk proses ke CY yang dapat dilihat pada gambar 4.4. dan versi TPKS, pada jalur merah peti kemas hanya 6,16 hari dan pada jalur hijau hanya 4 hari dengan demikian untuk jalur merah masih ada kendala karena TPKS sendiri tidak mempunyai data tanggal PIB dan SPPB secara detail. Tanggung jawab TPKS terhadap dwelling time sangat kecil, tidak ditemukan kendala yang signifikan di TPKS pada dwelling time hanya beberapa kendala minor saat pergerakan container ke Container Yard (CY). Penyumbang dwelling time yang paling tinggi adalah pengguna jasa baik jalur merah, kuning dan hijau.

Dwelling time di TPKS berkisar 4 hari termasuk didalamnya peti kemas isi dan kosong (berdasar data yang dikirim dari INSW), dengan demikian angka tersebut masih dalam kewajaran dan batas tertinggi yang berpengaruh ke biaya dwelling time adalah setelah 5 hari seperti yang tertera pada gambar 4.1., dan setelah itu kontainer harus dikeluarkan ke Pindah Lokasi Penumpukan (PLP). Di dalam Teori Kendala yang dikenal dengan Five Focusing Steps atau 5 langkah dasar yang langkah pertama adalah mengindentifikasi sistem kendala dimana sistem yang paling lemah bisa berupa kendala fisik atau kebijakan, pada gambar 4.1. langkah - langkah TPKS Pelabuhan Emas Semarang dalam kebijakan aturan sudah harus mengeluarkan kontainer baik kontainer isi maupun kosong ke PLP yang tentunya biaya logistiknya akan lebih mahal. Selanjutnya setelah 10 hari harus dipindahkan lagi ke depo swasta yang semakin mahal lagi biaya logistiknya. Oleh karena itu dengan adanya kebijakan dikeluarkannya kontainer setelah 5 hari, maka dapat ditekan $d$ welling time di TPKS pelabuhan Tanjung Emas Semarang.

Berdasarkan uraian di atas dapat diketahui bahwa hipotesis awal tentang faktor-faktor penyebab dwelling time antara lain: (a) kapasitas lahan penumpukan; (b) fasilitas bongkar muat yang digunakan masing-masing operator terminal; (c) tingkat kepadatan arus bongkar muat yang dilayani; dan (d) proses pengurusan dokumen kepabeanan untuk layanan ekspor impor sesuai dengan hasil penelitian dan mendukung penelitian Narindra dkk. (2016; 52).

\subsubsection{Dampak lamanya proses $d w e l l i n g$ time pada layanan ekspor dan impor di Pelabuhan Tanjung Emas}

Sesuai gambar 4.1. yang berdampak pada biaya logistik yang tinggi. Berbeda perlakuan bagi kontainer impor, karena saat barang masuk ke TPKS masih ada dokumen yang belum selesai karena masih ada pemeriksaan dari karantina maupun Bea Cukai, dengan demikian kontainer impor lebih tinggi dwelling time-nya.

Dalam dwelling time terdapat 3 tahapan yang dapat diklasifikasikan yaitu pre clearance, custom clearance dan post clearance. Berdasarkan ketersediaan data antara TPKS dan Bea Cukai, maka masing-masing pihak sudah mengetahui kendalanya seperti yang dijelaskan pada gambar 4.3. Pada keterangan di gambar 4.3. dijelaskan bahwa TPKS tidak mempunyai data tanggal PIB (Pemberitahuan Impor Barang) dan SPPB (Surat Perintah Pengeluaran Barang) dengan demikian akan menyulitkan TPKS untuk mengetahui berapa lama suatu kontainer di TPKS yang akan menyebabkan lamanya dwelling time.

Berdasarkan uraian di atas menunjukkan bahwa hipotesa awal tidak seluruhnya sesuai dengan hasil penelitian, sehingga hasil penelitian ini tidak mendukung penelitian Sandee (2012) dalam Anita dan Asmadewa (2017) .

3.2.3. Tindakan mitigasi yang diambil Pelabuhan Tanjung Emas Semarang untuk mengurangi dwelling time.

Tindakan yang dilakukan Pelabuhan Tanjung Emas Semarang dalam mengurangi dwelling time adalah mengatur integrasi detail antara TPKS dan Bea Cukai,apabila kontainer sudah lebih 5 hari harus segera dikeluarkan ke 
PLP, sehingga dwelling time dapat ditekan hingga 4 hari dan memberikan fasilitas 24 jam online dengan dilengkapi alat yang modern yaitu ARTG (Automated Rubber Tyred Gantry) serta otomasi gate.

\section{KESIMPULAN}

Kesimpulan yang diperoleh sebagai jawaban dari tujuan penelitian bahwa penyebab lamanya dwelling time di Pelabuhan Tanjung Emas adalah proses pemeriksaan dokumen dan fisik barang atas klasifikasi Kepabeanan pada jalur merah, kuning maupun hijau; untuk jalur merah masih ada kendala karena TPKS sendiri tidak mempunyai data tanggal PIB dan SPPB secara detail. Lama pemrosesan peti kemas di TPKS seringkali tidak diketahui; dan pengguna jasa baik jalur merah, kuning dan hijau yang seringkali tidak melengkapi dokumen secara jelas. Dampak lamanya proses $d w e l l i n g$ time pada layanan ekspor dan impor di Pelabuhan Tanjung Emas antara lain: proses ekspor tidak terlalu berpengaruh karena barang/peti kemas yang masuk TPKS dokumennya sudah selesai diproses; dwelling time proses impor lebih lama daripada ekspor karena barang/peti kemas yang masuk TPKS dokumennya belum selesai diproses, masih harus diperiksa karantina dan Bea Cukai. Selain itu tindakan mitigasi yang diambil Pelabuhan Tanjung Emas Semarang untuk mengurangi dwelling time antara lain: pengaturan integrasi secara detail antara TPKS dan Bea Cukai melalui fasilitas INSW sampai jam ke menit; adanya fasilitas 24 jam online dengan dilengkapi alat yang modern yaitu ARTG serta otomasi gate untuk memperlancar proses pengeluaran barang; kebijakan mengatur pengeluaran kontainer baik kontainer isi maupun kosong ke PLP setelah 5 hari dan setelah 10 hari harus dipindahkan lagi ke depo swasta; dan mengusulkan dilakukannya riset terhadap rantai cost logistics secara objektif dan menyeluruh, karena masalah dwelling time melibatkan banyak pihak.

\section{UCAPAN TERIMA KASIH}

Peneliti mengucapkan terima kepada Bapak Edy Sulaksono selaku mantan penjabat di Terminal Peti Kemas Semarang. Penelitian ini didanai melalui Penelitian ini dibiayai dengan Dana DIPA Politeknik Maritim Negeri Indonesia dengan Nomor: SP DIPA - 042.01.2.401035/2019 tanggal 5 Desember 2018 melalui Surat Perjanjian Nomor: 641.7/PL38/KS/2019.

\section{DAFTAR PUSTAKA}

Anita, S. L., \& Asmadewa, I. (2017). Analisis dwelling time impor pada Pelabuhan Tanjung Priok melalui penerapan theory of constraints. Jurnal perspektif bea dan cukai, 1(1).

Asngadi, S. (2017). Penjaluran barang impor jalur hijau, kuning dan merah. Diakses dari https:/indepnews.com/2017/11/penjaluran-barang-impor-jalur-hijau-kuning-dan-merah pada 26 Januari 2020, pukul 19.32.

Ghony, M. D., \& Almanshur, F. (2013). Metodologi Penelitian Kualitatif. Yogyakarta: Ar-Ruzz Media.

Gusnardi, G. (2010). TOC: Tinjauan teori. Jurnal Pendidikan Ekonomi dan Bisnis, 2(3), 336-345.

Narindra, R. A. A., Al Musadieq, M., \& Supriono, S. (2016). Analisis pengaruh dwelling time terhadap pendapatan (Studi pada PT. Terminal Petikemas Semarang tahun 2011-2015). Jurnal Administrasi Bisnis, 41(1), 51-56.

Nawawi, H., \& Mimi, M. (1996). Penelitian Terapan. Yogyakarta: Gajah Mada.

Prathama, U., Suwandi, R., \& Soeboer, D. A. (2017). Pengaruh aspek lapangan penumpukan terhadap dwelling time di TPK Koja. ALBACORE Jurnal Penelitian Perikanan Laut, 1(3), 349-359.

Ricardianto, P., Suhalis, A., \& Sirait, D. P. (2019). Integrasi antara dwelling time dan bongkar muat peti kemas Pelabuhan Tanjung Priok. Jurnal Manajemen Transportasi \& Logistik, 5(3), 193-204.

Sarjiyanto, S., \& Muslimin, K. (2017). Service of transportation and logistics at TPKS Semarang to shorten the dwelling time in AEC era. Jurnal Manajemen Teori Dan Terapan, 10(2), 136-149.

Sugiyono, P. D. (2011). Metode Penelitian Kuantitatif, Kualitatif, dan R\&D. Bandung: Alfabeta. 